\title{
Effects of Shrinkage Reducing Agent and Expansive Additive on Mortar Properties
}

\author{
Sarapon Treesuwan and Komsan Maleesee \\ Department of Civil Engineering, Faculty of Engineering, King Mongkut's Institute of Technology Ladkrabang, \\ Bangkok 10520, Thailand \\ Correspondence should be addressed to Sarapon Treesuwan; sarapon.t@hotmail.com
}

Received 15 May 2017; Revised 18 August 2017; Accepted 30 August 2017; Published 12 October 2017

Academic Editor: Jose M. Monzo

Copyright (c) 2017 Sarapon Treesuwan and Komsan Maleesee. This is an open access article distributed under the Creative Commons Attribution License, which permits unrestricted use, distribution, and reproduction in any medium, provided the original work is properly cited.

\begin{abstract}
This research is to study the effect of mortar mixed with shrinkage reducing agent (polyoxyalkylene alkyl ether type), expansive additive (CaO type), and fly ash (hereinafter "SRA," "EX," and "FA," resp.). Moreover, steam curing was studied to improve the properties of mortar. The plastic shrinkage test was conducted by using the strain gauge embedded at $0.5 \mathrm{~cm}$ from the surface according to the ASTM C1579-06 standard within early age followed by the total shrinkage test and compressive strength test. The test results showed that mixing both the EX and SRA increases the plastic enlargement of the mortar during the early age more than using either the EX or SRA solely. The steam curing helps to reduce the plastic shrinkage when the mortar is added with the FA and SRA while adding the EX increases the enlargement compared to the normal curing. When the EX, SRA, and FA are all added to the mortar mixing, great attention should be paid due to the increase of greater enlargement. For the compressive strength view, the steam curing increases the compressive strength in all types of mixture. The steam curing significantly helps increasing the compressive strength of mortar with combination of EX, SRA, and FA. Nevertheless, the XRD and SEM tests explain such enlargement accordingly.
\end{abstract}

\section{Introduction}

The shrinkage and cracking usually occur while mortar is in the hardening process. Such the shrinkage occurs both from the hydration reaction and from the environment. The shrinkage of mortar can be divided into 2 main stages, that is, the early age (within the first 24 hours) and the long term (after the first 24 hours) [1]. The surface cracking of mortar occurs mostly during the early age of the construction. The surface cracking can be measured in the view of plastic shrinkage and there is a strong possibility that the cracking should occur in all parts of the building with high surface area, for example, the wall, the floor, the roof top, and the platform. From the preceding research $[2,3]$, it is explained that the plastic shrinkage occurs owing to the rapid evaporation of the humidity on the paste's surface which affects the immediate shrinkage during the prehardened stage whereas the paste in this stage is almost entirely unable to tolerate the tensile stress near the surface while the paste shrinks. When the stress is harder than the paste's tolerability, the cracking then occurs. There are many ways of reducing the shrinkage of mortar. One of the ways is to use such an additive inorganic material as the fly ash (FA) and the shrinkage reducing agent (SRA), which is a kind of chemical substance that helps reducing the surface tension by dropping the capillary stress and, hence, reducing the shrinkage of the paste in terms of both the chemical reaction and the external environment. The expansive additives (EX) generally help reducing the shrinkage due to many different factors, for example, the enlargement from water absorption and the forming of the pore and crystal structure in the process of hydration reaction [4]. The SRA and EX can be simply added during the mixing process requiring no additional equipment. Nevertheless, to add such additives reduces the strength of mortar [5-7]. A way to enhance the strength is to perform the steam curing by giving the humidity and heat to the newly molded cement helping the paste not to dehydrate and reducing the water evaporation on the surface along with increasing the catalysis 
TABLE 1: Materials.

\begin{tabular}{|c|c|c|c|}
\hline & Kind & Symbol & $\begin{array}{l}\text { Physical properties, main } \\
\text { component }\end{array}$ \\
\hline Cement & Ordinary Portland Cement & $\mathrm{C}$ & ASTM C150 \\
\hline \multirow{2}{*}{ Inorganic additive } & Fly ash & FA & ASTM Type C \\
\hline & Expansive additive & EX & Free-lime type \\
\hline Admixture & Shrinkage reducing agent & SRA & Polyoxyalkylene alkyl ether \\
\hline
\end{tabular}

TABLE 2: Mix proportion.

\begin{tabular}{lcccc}
\hline Chemical composition & $\mathrm{C}$ & $\mathrm{FA}$ & EX & SRA \\
\hline $\mathrm{SiO}_{2}(\%)$ & 21.5 & 24 & - & \\
$\mathrm{Al}_{2} \mathrm{O}_{3}(\%)$ & 4.64 & 10 & - & - \\
$\mathrm{Fe}_{2} \mathrm{O}_{3}(\%)$ & 3.05 & 21.2 & 0.45 & - \\
$\mathrm{CaO}(\%)$ & 65 & 32.6 & 77.5 & - \\
$\mathrm{MgO}(\%)$ & 0.88 & 2.08 & 0.51 & - \\
$\mathrm{Na}_{2} \mathrm{O}(\%)$ & 0.09 & 0.1 & - & - \\
$\mathrm{K}_{2} \mathrm{O}(\%)$ & 0.59 & 3.57 & 5.3 & - \\
$\mathrm{SO}_{3}(\%)$ & 2.47 & 1.1 & 16.2 & - \\
$\mathrm{Specific}$ gravity & 3.15 & 2.23 & 3.16 & 0.99 \\
$\left.\mathrm{Specific} \mathrm{surface}_{(\mathrm{cm}}^{2} / \mathrm{g}\right)$ & 3,400 & 3,800 & 3,450 & - \\
\hline
\end{tabular}

between the water and cement to enhance the paste's strength rapidly and to increase the surface quality [8]. As a result, the steam curing is considered suitable for enhancing the strength when the additive is added. However, there is a small amount of preceding researches regarding this article and those researches do not cover the steam curing. This research therefore emphasizes the effect of mortar with the SRA and EX added including the FA by using the product that can easily be found in the market and on the steam curing under normal pressure in order to learn the tolerability and shrinkage of mortar.

\section{Outline of Experiment}

2.1. Materials. The following are materials used in the test: Ordinary Portland Cement (C), fly ash (FA) from Mae Moh Power Plant in Lampang Province, Thailand, calcium oxidebased expansive additive (EX), and polyoxyalkylene alkyl ether shrinkage reducing agent (SRA). The detail of materials used is shown in Table 1. The chemical composition is shown in Table 2. The sand used in this test is due to the ASTM C 778 graded sand, with fineness modulus (FM) of 3.05, 0.54\% absorption, bulk specific gravity of 2.58 , and bulk SSD specific gravity (saturated surface dry) of 2.60 .

In this regard, the ratio between powder (B) and sand (S) was determined as $1: 2.75$, the water was replaced with the SRA at $2 \%$ according to the amount of powder $(B)=(C$ $+\mathrm{FA}+\mathrm{EX})$, and the powder (B) was replaced with the EX $=$ at $15 \%$ stable while mixing both $\mathrm{FA}+\mathrm{EX}$ with $\mathrm{FA}(\%)=$ $((\mathrm{B})-\mathrm{EX}) * \mathrm{C} \%$; the Hobart mixer was used to mix the mortar, water, and admixture at low speed for 15 seconds. Then the weighed powder was added using low speed mixing for 30 seconds, at medium speed for 90 seconds and at high speed for 160 seconds (i.e., overall mixture of 3 minutes). The water demand of the mixture (W/B ratio) was tested by the flowing rate evaluation according to the ASTM C230. The flowing rate of mortar was controlled at $105 \%$. The mixture ratio and testing condition are shown in Table 3.

\subsection{Methods}

2.2.1. Initial Setting Time and Final Setting Time. To count the initial setting time was conducted at room temperature (i.e., $25^{\circ} \mathrm{C}$ ) by penetration resistance in order to determine the starting point for measuring the shrinkage during the early age and the final setting time for all types of mixture by using the Vicat needle apparatus according to the ASTM C807 standard. The initial setting time of the mortar was when the plugger sank in for $10 \pm 1 \mathrm{~mm}$ from the top surface.

2.2.2. Bleeding. The test by JIS A1123 method was conducted (referred to as the JCI test method) [9]. The sample was poured into the bleeding test kit. The test kit was marked at the equal volume as the mortar (i.e., approximately $400 \mathrm{ml}$ ). After pouring, the water volume on the surface of the mortar was recorded. The recording was performed repeatedly after every 30 minutes for at least 6 hours altogether.

2.2.3. Plastic Shrinkage. The plastic shrinkage determination during the early age can be determined following the ASTM C1579-06 standard. The determination can be done by several different patterns, for example, photographing the cracking on the surface by the microscope [10], measuring the width of the cracking on the surface by using the LVDT or Laser sensors $[11,12]$, and bedding the strain gauge directly into the mold [4]. The use of strain gauge gives approximate results with the use of laser equipment and contact gauge [12]. In this research, the water proof strain gauge was used with operating temperature range from -10 to $70^{\circ} \mathrm{C}$ bedded in the center of the mold on top of the crack riser installed at $0.50 \mathrm{~cm}$ from the surface. The movement was measured and recorded every 10 minutes starting from the initial setting time for 24 hours, and the shrinkage test was done at $30^{\circ} \mathrm{C}$ (normalcured), $60 \% \pm 5 \% \mathrm{RH}$, and steam-cured at $65^{\circ} \mathrm{C}$, with $95 \%$ $\mathrm{RH}$ by the steam curing machine. In this regard, the steaming duration is important. The preceding researches mostly spent 24 hours for the steam curing which was considered sufficient and effective in the strength enhancing [13-15]. Therefore, the heat cycle ( 1 day cycle) was also used in this research. 
TABLE 3: Mixture proportions of the mortars.

\begin{tabular}{|c|c|c|c|c|c|c|c|c|c|c|c|c|}
\hline \multirow[t]{2}{*}{ Mix number } & \multirow[t]{2}{*}{ Sample } & \multirow[t]{2}{*}{$\mathrm{W} / \mathrm{B}$} & \multirow{2}{*}{$\begin{array}{l}\text { EX } \\
(\%)\end{array}$} & \multirow{2}{*}{$\begin{array}{c}\text { SRA } \\
(\%)\end{array}$} & \multirow{2}{*}{$\begin{array}{l}\text { FA } \\
(\%)\end{array}$} & \multicolumn{6}{|c|}{$\begin{array}{l}\text { Unit weight } \\
\qquad\left(\mathrm{kg} / \mathrm{m}^{3}\right)\end{array}$} & \multirow{2}{*}{$\begin{array}{l}\text { Unit weight in } \\
\text { fresh state } \\
\left(\mathrm{kg} / \mathrm{m}^{3}\right)\end{array}$} \\
\hline & & & & & & $\mathrm{W}$ & $\mathrm{C}$ & EX & SRA & FA & S & \\
\hline (1) (control) & $\mathrm{C}$ & \multirow{10}{*}{0.7} & 0 & \multirow{4}{*}{0} & \multirow{2}{*}{0} & 337 & 482 & 0 & 0 & 0 & 1,325 & 2,144 \\
\hline (2) & $\mathrm{C}+\mathrm{EX}$ & & \multirow{3}{*}{15} & & & 337 & 410 & 72 & 0 & 0 & 1,325 & 2,145 \\
\hline (3) & $\mathrm{C}+\mathrm{EX}+\mathrm{FA} 20$ & & & & 20 & 334 & 324 & 72 & 0 & 81 & 1,311 & 2,122 \\
\hline (4) & $\mathrm{C}+\mathrm{EX}+\mathrm{FA} 40$ & & & & 40 & 330 & 241 & 71 & 0 & 160 & 1,297 & 2,100 \\
\hline (5) & $\mathrm{C}+\mathrm{SRA}$ & & \multirow{4}{*}{0} & \multirow{4}{*}{2} & 0 & 328 & 482 & 0 & 10 & 0 & 1,325 & 2,144 \\
\hline (6) & $\mathrm{C}+\mathrm{SRA}+\mathrm{FA} 20$ & & & & 20 & 324 & 381 & 0 & 10 & 95 & 1,309 & 2,117 \\
\hline (7) & $\mathrm{C}+\mathrm{SRA}+\mathrm{FA} 40$ & & & & 40 & 320 & 282 & 0 & 9 & 188 & 1,292 & 2,091 \\
\hline (8) & $\mathrm{C}+\mathrm{EX}+\mathrm{SRA}$ & & & & 0 & 328 & 410 & 72 & 10 & 0 & 1,325 & 2,144 \\
\hline (9) & $\mathrm{C}+\mathrm{EX}+\mathrm{SRA}+\mathrm{FA} 20$ & & \multirow[t]{2}{*}{15} & & 20 & 324 & 324 & 72 & 10 & 81 & 1,311 & 2,122 \\
\hline$(10)$ & $\mathrm{C}+\mathrm{EX}+\mathrm{SRA}+\mathrm{FA} 40$ & & & & 40 & 321 & 241 & 71 & 9 & 160 & 1,297 & 2,099 \\
\hline
\end{tabular}

Note. W: water, C: cement, EX: expansive additive, SRA: shrinkage reducing agent, FA: fly ash, and S: sand.

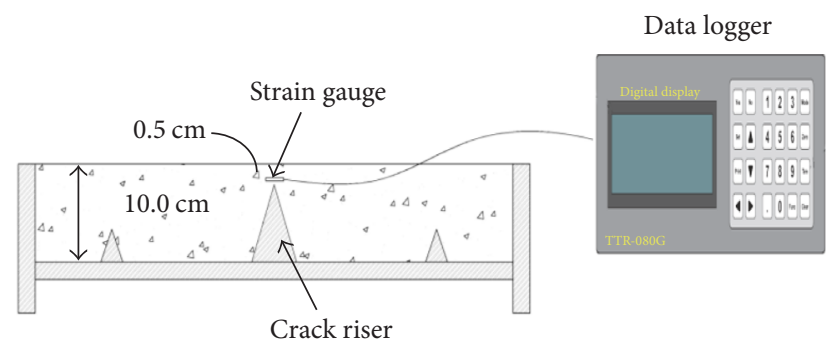

FIGURE 1: Schematic of the mold and specimen.

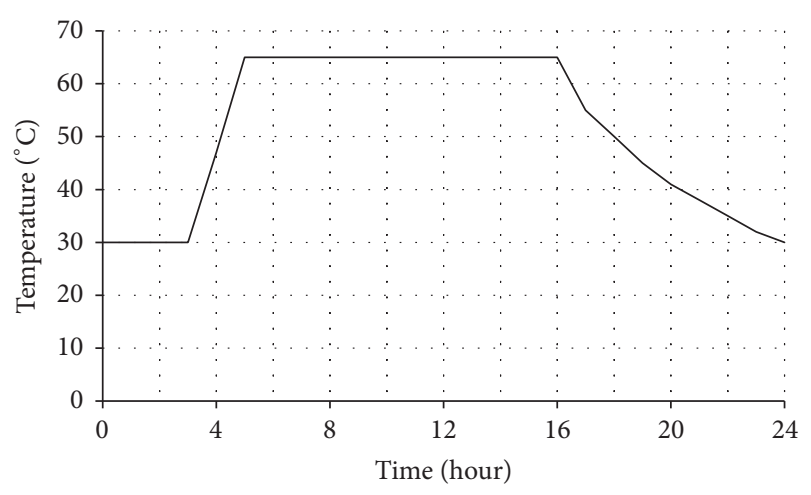

FigURE 2: Steam curing temperature.

Before the steam curing was conducted, the mortar was left in its hardening period during the early age by leaving it for approximately 3 hours depending on the initial setting time at room temperature $\left(30^{\circ} \mathrm{C}\right)$, with $60 \pm 5 \% \mathrm{RH}$, and thence raised the temperature at the stable rate $\left(20^{\circ} \mathrm{C}\right.$ per hour) until the temperature reached $65^{\circ} \mathrm{C}, 95 \pm 5 \% \mathrm{RH}$. The temperature and humidity were controlled at this period for 10 hours before lowering the temperature slowly to normal stage. The plastic shrinkage measurement is shown in Figure 1 and the temperature used in the steam curing is shown in Figure 2.

2.2.4. Compressive Strength. The samples from each mixture were kept in the $5 \times 5 \times 5 \mathrm{~cm}$ square molds according to the
ASTM C 109 standard and removed after 24 hours, and thence the steam curing was repeated at room temperature $\left(30^{\circ} \mathrm{C}\right)$. The compressive strength was tested after 1 day, 3 days, 7 days, and 28 days.

2.2.5. Total Shrinkage. The total shrinkage was measured according to the JIS A1129 standard in the $4 \times 4 \times 16 \mathrm{~cm}$ molds. Two LVDTs were installed at each end of the samples in order to use as the shrinkage determination point. The test was done every 24 hours for 28 days in the controlled temperature of $25^{\circ} \mathrm{C}$ and $40 \% \mathrm{RH}$.

2.2.6. Microstructure Characterization. The samples were prepared by metal coating and photographed by the Scanning Electron Microscope (SEM) in order to study the microstructures in hydration products of mortar at the sixth hour after mixing. The samples were tested to study the quantity of chemical substances in the mortar by using the XRD machine.

\section{Results}

3.1. Setting Time. The initial setting time and the final setting time of the mortar are shown in Table 4.

When the ratio of replacing the cement with the EX was raised, the initial setting time reduced for 11 minutes compared to the controlled mortar and also reduced the final setting time. The initial setting time of the mortar with the EX added tended to reduce when the ratio of replacing the cement was raised. However, when the ratio of replacing the cement with the FA was raised, both the initial setting time and the final setting time increased considerably (for $\mathrm{EX}+\mathrm{FA} 20$ and EX + FA40). When the water was replaced by the SRA for $2 \%$, the initial setting time of the mortar increased. When the ratio of adding the FA was at $20 \%$ and $40 \%$ (SRA + FA20 and SRA + FA40), the initial setting time increased considerably. To add the EX and the SRA (EX + SRA) prolonged the initial setting time but the final setting time was close to that of the controlled mortar. However, when the ratio of the FA added was raised $(\mathrm{EX}+\mathrm{SRA}+\mathrm{FA} 20$ 
TABLE 4: Initial setting time and final setting time of mortar mixed with EX, SRA, and FA.

\begin{tabular}{|c|c|c|}
\hline \multirow{2}{*}{ Sample } & \multicolumn{2}{|c|}{ Setting time } \\
\hline & Initial & Final \\
\hline $\mathrm{C}$ & $2 \mathrm{~h} 30 \mathrm{~min}$ & $6 \mathrm{~h} 17 \mathrm{~min}$ \\
\hline $\mathrm{C}+\mathrm{EX}$ & $2 \mathrm{~h} 19 \mathrm{~min}$ & $5 \mathrm{~h} 13 \mathrm{~min}$ \\
\hline $\mathrm{C}+\mathrm{EX}+\mathrm{FA} 20$ & $3 \mathrm{~h} 13 \mathrm{~min}$ & $6 \mathrm{~h}$ \\
\hline $\mathrm{C}+\mathrm{EX}+\mathrm{FA} 40$ & $4 \mathrm{~h} 5 \mathrm{~min}$ & $6 \mathrm{~h} 45 \mathrm{~min}$ \\
\hline $\mathrm{C}+\mathrm{SRA}$ & $2 \mathrm{~h} 50 \mathrm{~min}$ & $6 \mathrm{~h} 26 \mathrm{~min}$ \\
\hline $\mathrm{C}+\mathrm{SRA}+\mathrm{FA} 20$ & $3 \mathrm{~h} 15 \mathrm{~min}$ & $5 \mathrm{~h} 29 \mathrm{~min}$ \\
\hline $\mathrm{C}+\mathrm{SRA}+\mathrm{FA} 40$ & $4 \mathrm{~h} 15 \mathrm{~min}$ & $6 \mathrm{~h} 26 \mathrm{~min}$ \\
\hline $\mathrm{C}+\mathrm{EX}+\mathrm{SRA}$ & $3 \mathrm{~h} 19 \mathrm{~min}$ & $6 \mathrm{~h} 20 \mathrm{~min}$ \\
\hline $\mathrm{C}+\mathrm{EX}+\mathrm{SRA}+\mathrm{FA} 20$ & $3 \mathrm{~h} 52 \mathrm{~min}$ & $8 \mathrm{~h} 20 \mathrm{~min}$ \\
\hline $\mathrm{C}+\mathrm{EX}+\mathrm{SRA}+\mathrm{FA} 40$ & $4 \mathrm{~h} 39 \mathrm{~min}$ & $9 \mathrm{~h} 44 \mathrm{~min}$ \\
\hline
\end{tabular}

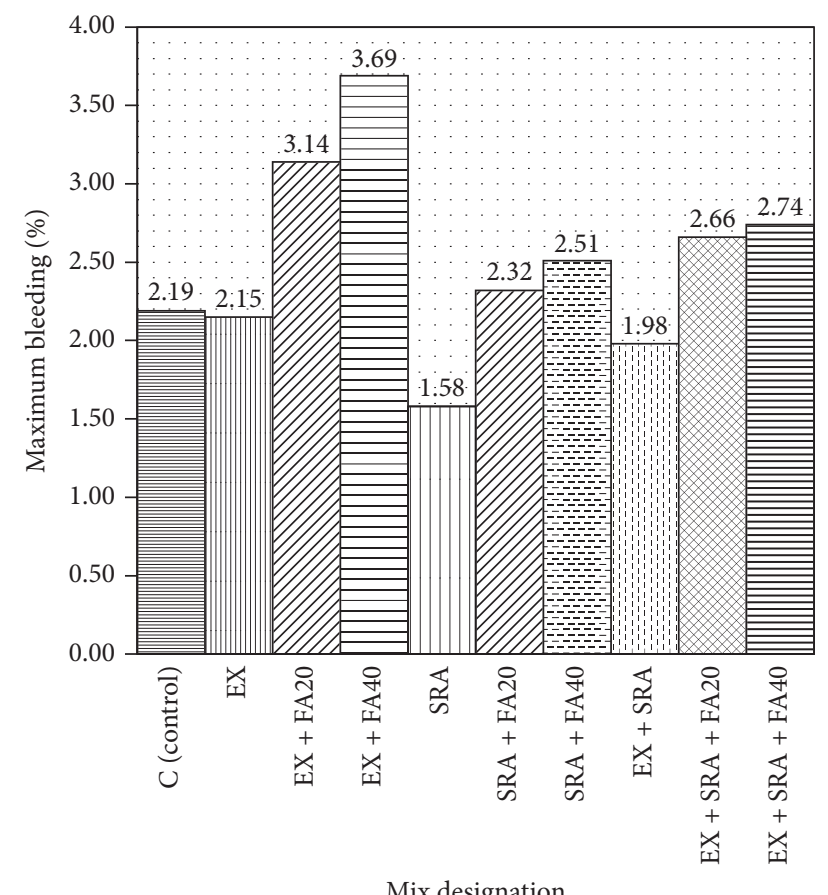

FIGURE 3: Bleeding of mortar mixed with EX, SRA, and FA.

and EX + SRA + FA40), both the initial setting time and the final setting time increased considerably especially while EX + SRA + FA40 prolonged both the initial setting time and the final setting time for 2.09 hours and 3.27 hours, respectively, longer than the controlled mortar.

3.2. Bleeding. From Figure 3, when the EX was solely added, the bleeding rate slightly decreased compared to the controlled mortar but when the FA was added to both EX + FA20 and EX + FA40, the bleeding rate increased considerably. The results correspond to the test result of the prolonged initial setting time. The adding of the FA may have reduced the hydration reaction which produced the excess water resulting

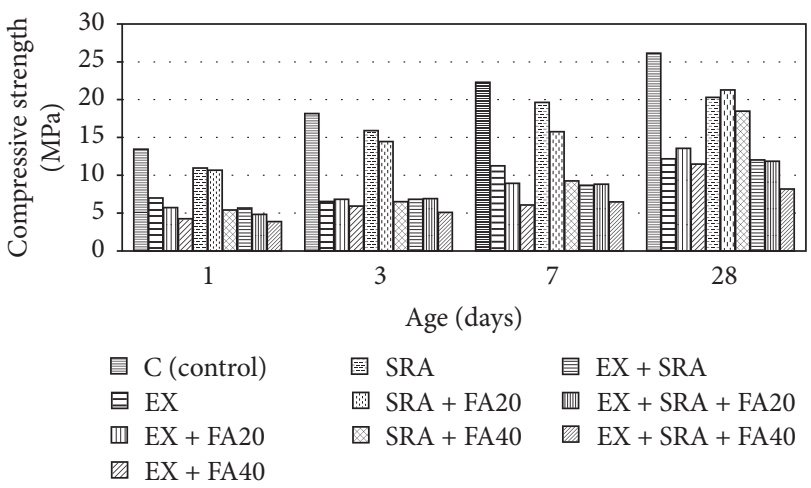

FIGURE 4: Compressive strength of normal-cured mortar.

in the fact that the water particle floated onto the surface. The adding of the SRA reduced the bleeding for $27.85 \%$ compared to the controlled mortar and the tendency of the bleeding rate of SRA + FA rose when the ratio of the FA was raised. The bleeding rate, in this regard, correspond to that of Bentz et al's test [16] where the mass loss and the humidity in the paste with the SRA added were conducted. The mass loss of the paste with SRA added reduced more than the paste without SRA and the relative humidity was higher in the paste with SRA added. As well as the EX + SRA + FA20 and EX + SRA + FA40, the bleeding rate was still low compared to mixing with the EX solely. As such, when the SRA was added, it acted as the curing layer. Furthermore, the fact that the SRA reduced the surface tension also helped keeping the water in the paste while, compared to the case without the SRA added, the water in the capillary pore has a higher volume of surface tension, and the water from the lower layer with lower surface tension is hence pulled out in order to replace the water lost on the surface due to the hydration reaction and the environment $[16,17]$.

3.3. Compressive Strength. The compressive strength of normal curing is shown in Figure 4. The compressive strength of controlled mortar was $13.4 \mathrm{Mpa}$. To replace the cement with the EX for $15 \%$ reduced the compressive strength considerably by $47.77 \%$ (6.4 Mpa) within the first day after the mixing compared to the controlled mortar. The mixing of EX + FA reduced the strength slightly as the ratio of the FA rose. This shows that the main factor is the EX. To replace the water with the SRA for $2 \%$ slightly reduced the compressive strength by $17.91 \%(2.4 \mathrm{Mpa})$ compared to the controlled mortar. The mixing of SRA + FA reduced the compressive strength of the mortar as the raised ratio of the FA. The mixing of SRA + FA20 and SRA + FA40 and the compressive strength at 1 day old reduced by $20.15 \%$ (2.7 Mpa) and 59.7 (8.0 Mpa), respectively, compared to the controlled mortar. Therefore, the basic necessity of the mortar's compressive strength depends on the amount of the FA added, especially being added for 40\%; this extremely reduced the compressive strength. With EX + SRA added, the mortar's compressive strength reduced considerably both during the first day and at 28 days old; that is, the compressive strength was at $57.46 \%$ (7.7 Mpa) compared to the one-day-old controlled mortar 


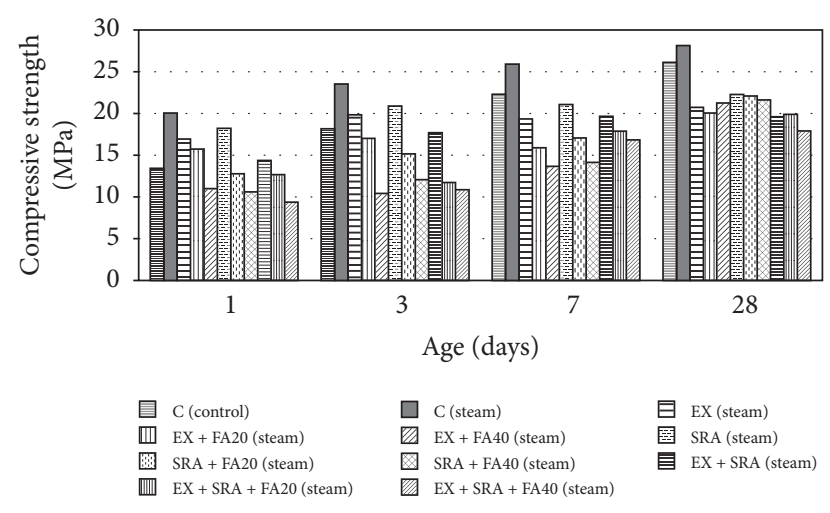

Figure 5: Compressive strength of steam-cured mortar.

and at $49.58 \%$ (11.8 Mpa) compared to the twenty-eight-dayold mortar. For the mixing of EX + SRA + FA, the mortar's strength in the initial and final age tended to reduce in accordance with the amount of the FA increasingly added, especially when the FA was added at $40 \%$, the compressive strength extremely reduced by $70.89 \%$ ( $9.5 \mathrm{Mpa}$ ) compared to the controlled mortar, but when the FA was added at $20 \%$, the compressive strength slightly reduced, that is, close to mixing only the EX + SRA.

The steam curing at $65^{\circ} \mathrm{C}$ is shown in Figure 5. The compressive strength of mortar that has been steam-cured is higher than being cured at $30^{\circ} \mathrm{C}$ in all cases compared to those of the same types of mixture. The tendency of the compressive strength with the EX, SRA, and FA added is generally close to the normal curing at $30^{\circ} \mathrm{C}$. The strength of mortar increased considerably for all types of mixture when the test was done 1 day after mixing due to the increasing of hydration reaction of the cement and pozzolanic reaction of the additive from raising the temperature [18]. The steam curing considerably helps increasing the compressive strength of the EX by $241.42 \%$ (9.9 Mpa) compared to the curing at normal temperature. Further result is that the compressive strength is stronger than the controlled mortar within the first day after mixing.

The strength index of the mortar that has been through the normal curing and the steam curing at $65^{\circ} \mathrm{C}$ compared to the controlled mortar is shown in Figures 6 and 7, respectively. The results clearly show that the steam curing considerably helps increasing the compressive strength for all types of mixture. An interesting result to be noted in the normal curing is that to see the great gap of strength since after the first 24 hours until 28 days, as shown in Figure 7. For the steam curing, the strength index of the controlled mortar that has been through the steam curing reduced after times, that is, close to the controlled mortar that has been through the normal curing for 28 days. However, in case of mortar mixed with the EX, EX + FA, EX + SRA, and EX + SRA + FA, the strength index of mortar tended to rise, which shows that the gap of strength becomes narrower as shown in Figure 8. This shows that the steam curing benefitted the strength of mortar with the EX and SRA added both in the early age and in the long run.

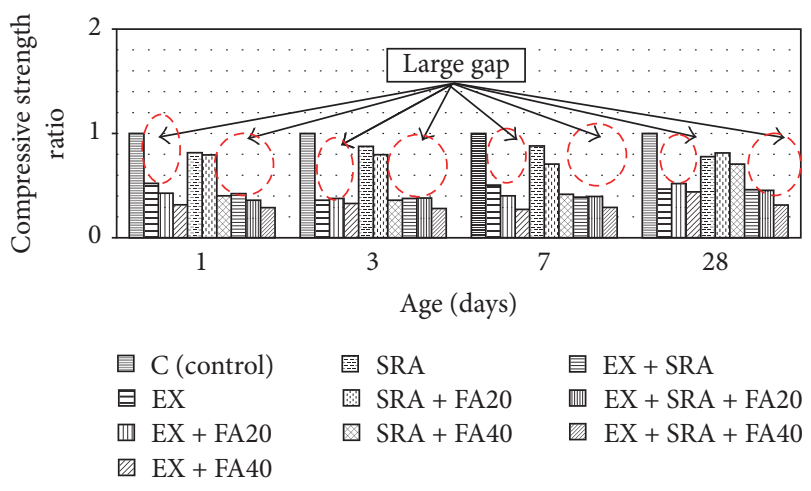

FiguRE 6: Compressive strength ratio of normal-cured mortar.

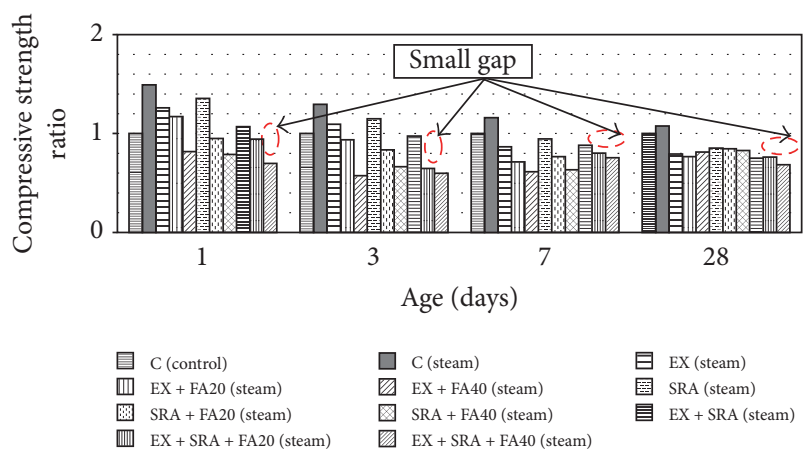

FIGURE 7: Compressive strength ratio of steam-cured mortar.

The compressive strength of mortar with the EX and SRA added including the FA in this research tended to reduce as commonly appeared in many other researches. For the EX, Carballosa et al. [5] mixed the EX in the self-compacting concrete and the FA for $7.5 \%$ and $10 \%$, respectively, and found that, during the first date, the compressive strength did not depend on the amount of the EX but the compressive strength reduced after the 7th date and the compressive strength reduction was $5 \mathrm{MPa}$ (i.e., 12.8\%) when the age was 28 days. This was especially the calcium base type of EX; the compressive strength reduced for $25 \%$ for 28 days. There are small amounts of research on the EX + SRA and EX + SRA + FA. Monosi et al. [6, 7] found that the compressive strength reduced when the EX + SRA was added. For the EX + SRA + FA, the compressive strength of mortar with the EX was added for $0-7.5 \%$, SRA for $0-0.75 \%$, and stable FA for $10 \%$. For the mixing of all types of mixture, the compressive strength clearly reduced when the proportion of the EX was higher than $7.5 \%$.

\subsection{Shrinkage Test}

3.4.1. Effect of $E X$ and $E X+F A$. Figure 8 shows the shrinkage rate of mortar with the EX and EX + FA added during the early age. The mortar with EX added that has been steamcured increasing the enlargement for 196.85\% (921 microstrain) compared to the normal curing while the steam curing considerably increased. The initial high rate of enlargement 


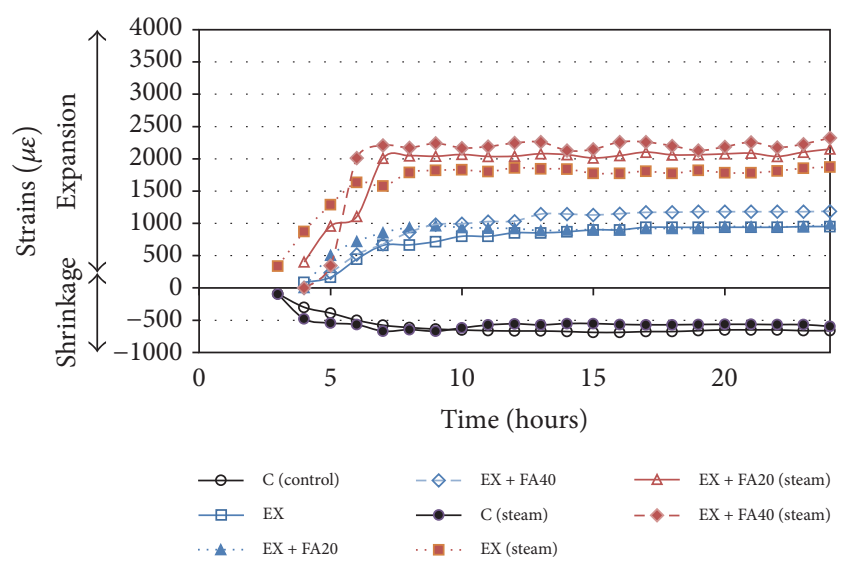

FIgURE 8: Early age plastic shrinkage results for EX and EX + FA.

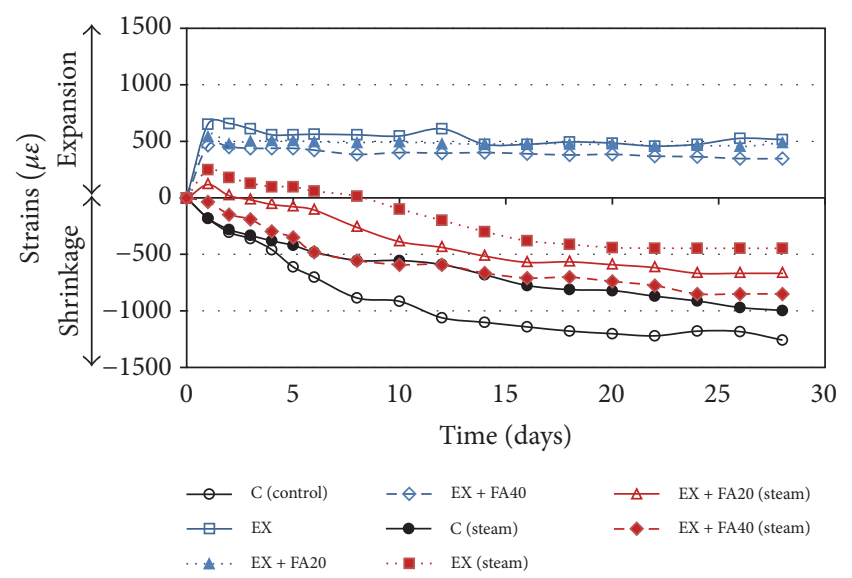

FIgure 9: Total shrinkage results for EX and EX + FA (1 day after mixing).

might have pointed to the fact that the pozzolanic reaction rate of the EX was fast in accordance with the faster initial setting time test result as shown in Table 4. Yazici et al. [13] reported that when the temperature of the curing was high, $\mathrm{CaO}$ would act faster. The enlargement rate started to decrease after approximately 10 hours for the normal curing and 6 hours for the steam curing. The normal curing for mortar with EX + FA added for $20 \%$ and $40 \%$ showed that the enlargement during the early age increased in accordance with the amount of FA replaced. In addition, this enlargement may explain that, as the amount of required water decreased, the exceeding water occurred which resulted in prolonging the evaporation period of the water on the surface and that to replace the cement reduced the hydration reaction between the cement and water which was one of the causes of the shrinkage. Furthermore, the FA is naturally smaller and smoother than the cement and, with its natural rounded form, allowing less pores which reduces the shrinkage [19]. The shrinkage reducing nature of the FA was also found in other types of mixture in this test.

Figure 9 shows the enlargement of mortar with the EX and EX + FA added that has been through the normal

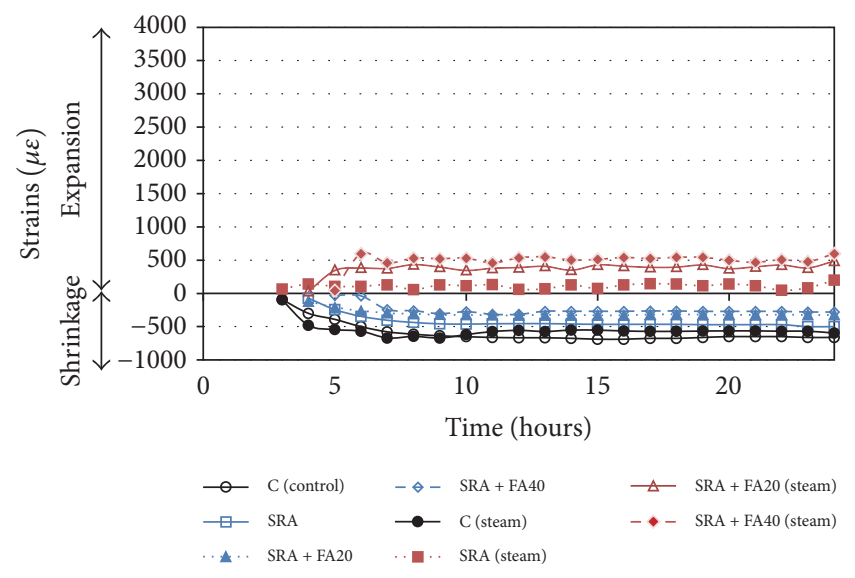

FIGURE 10: Early age plastic shrinkage results for SRA and SRA + FA.

and steam curing by recording the result 24 hours after mixing. The tendency of the normal curing conformed to the shrinkage during the early age; that is, when more amount of the cement was replaced by the EX, the enlargement also increased. The enlargement of the EX occurred and ended during the first 2 days. For the steam curing, the mortar with EX + FA added appeared to be slightly enlarged and extremely shrunk. The shrinkage rate that rose in accordance with the rising amount of FA added may be from the fact that when the $\mathrm{CaO}$ reacted with $\mathrm{H}_{2} \mathrm{O}$ in order to create $\mathrm{Ca}(\mathrm{OH})_{2}$, the amount of calcium hydroxide increased which enlarged the paste; thence the calcium hydroxide reaction became into the pozzolanic reaction with the FA which affected the shrinkage and increased the compressive strength [20].

3.4.2. Effect of SRA and SRA + FA. The adding of SRA and SRA + FA reduced the shrinkage during the early age for all types of mixture as shown in Figure 10. The normal curing reduced $24.50 \%$ (162 microstrain) of the plastic shrinkage compared to the controlled mortar. Slight enlargement was found in the steam curing during the early age. For SRA + FA, the normal curing slightly helped reducing the shrinkage; that is, the shrinkage reduced as the amount of FA replaced rose while, in case of the steam curing, the enlargement considerably increased. This enlargement tendency during the early age confirms the test results of Corinaldesi [21] and Sant et al. [22] which found that to add the SRA made the crystallization stresses more than the normal paste during the early age since, during the early age, the paste was saturated by the large number of water which increased the amount of portlandite more than the normal paste resulting in the enlargement during the early age. In addition, the elongated portlandite crystals were found 26 hours after mixing. Therefore, after considering the fact, the steam curing increases the amount of water in the paste and deepened the hydration reaction which increases the amount of portlandite and ettringite considerably. This is clearly seen as photographed by the SEM as shown in Figure 15. The small pores are found in large number compared to the normal curing. Such shrinkage may 


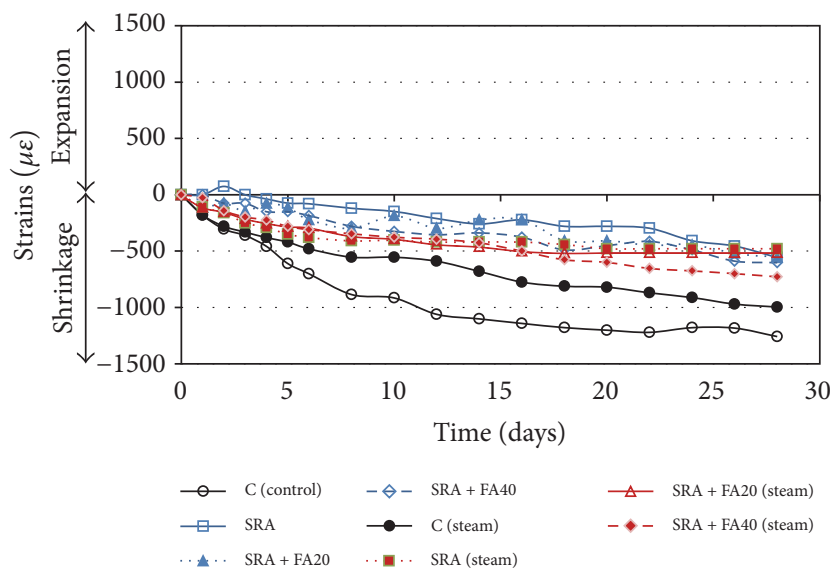

FIGURE 11: Total shrinkage results for SRA and SRA + FA (1 day after mixing).

be explained by Young-Laplace relation; that is, the simple equation [23] is as follows:

$$
\rho^{\prime \prime}-\rho^{\prime}=\frac{2 \sigma \cos \theta}{r}
$$

where $\rho^{\prime \prime}$ is capillary pressure of steam curing tension, $\rho^{\prime}$ is capillary pressure of normal curing tension, $\sigma$ is surface tension of the pore solution, $\theta$ is wetting angle, and $r$ is radius of the meniscus.

The pore size reduces both from the FA added and from the curing [23]. When the pore size reduces, the capillary pressure increases. Meanwhile, the SRA that reduces the surface tension results in the reduction of capillary pressure. This is one of the factors that explains how the shrinkage occurs after curing. Moreover, from the equation, to study the results from adding only the SRA (as shown in Figures 10 and 11), the steam curing somehow helps preventing the surface from evaporation (i.e., $\theta=0$ ), which conforms to the test results in this research finding insignificant differences on the shrinkage when the normal and steam curing are compared. Therefore, to add only the SRA slightly helps for the steam curing during the early age.

Nevertheless, from the bleeding test results shown in Figure 3, although to add the SRA reduces the amount of bleeding lower than the controlled mortar, it shows that the water bleeding on the surface is not the basic necessity that importantly affects the plastic shrinkage of the SRA during the early age. The long-term shrinkage of the SRA and SRA + FA is shown in Figure 11. The influences of the SRA were also found during the first 3 days; that is, slight enlargement was also found in case of the normal curing but extreme shrinkage was found in case of the steam curing since the first date. The shrinkage also increased in accordance with the increasing amount of the FA added.

3.4.3. Effect of $E X+S R A$ and $E X+S R A+F A$. The enlargement of mortar with EX + SRA and EX + SRA + FA added during the early age is shown in Figure 12. For the normal curing, the enlargement increased considerably when the

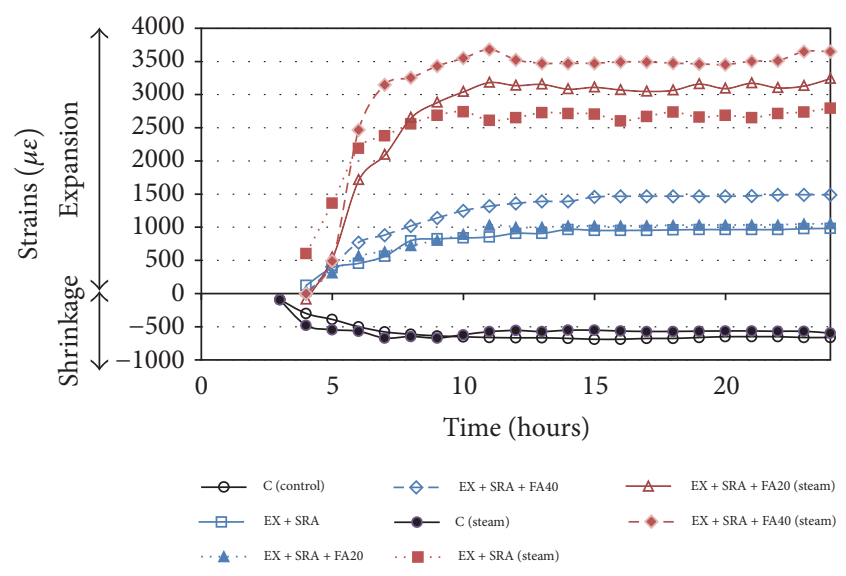

FIGURE 12: Early age plastic shrinkage results for EX + SRA and EX + SRA + FA.

amount of FA was added by $40 \%$. For the steam curing, the enlargement increased considerably in cases EX + SRA, EX + SRA + FA20, and EX + SRA + FA40. In this regard, the mortar was enlarged by $284 \%, 307 \%$, and $244 \%$, respectively, compared to the normal curing. Therefore, the amount of FA added to the mixture highly affects the enlargement. It is said that to add the FA helps decreasing the amount and reducing the size of the pores in the paste. The steam curing also reduces the size of the pores [14]. In case of adding the EX + SRA, Maltese et al. [24] explained such the enlargement by using the XRD and found the increase of Ettringite and Portlandite in larger amount compared to the sole adding of either EX or SRA. The steam curing extremely enlarges the EX + SRA + FA. The hydration products are considerably found as a result of the steam curing and the particle form of mortar becomes entirely different in this regard. Figure 16 shows the photograph taken by the SEM of the steam curing for mortar mixed with EX + SRA 6 hours after mixing. The small pores are seen in case of adding the EX + SRA + FA. The steam curing is the best way to increase the enlargement of the mortar. Figure 17 shows the photograph taken by the SEM of the steam curing for mortar mixed with EX + SRA + FA40 6 hours after mixing. The physical characteristics of the hydration products that change during the early age show the significant properties that change both regarding the strength and the shrinkage with long thick needle particles found all over the surface of the FA which is significantly longer and larger in size compared to the normal curing. This clearly confirms the plastic shrinkage test results regarding the influences of the steam curing that extremely increases the enlargement. Such an extreme enlargement occurs from several factors and one of the factors is from replacing the cement with the FA. Nevertheless, the ASTM C157 determines that the mortar's enlargement should not exceed $0.02 \%$. Therefore, the environment and curing method are highly suggested to be considered to determine the amount and proportion of the SRA and EX allowed to be added.

In addition, the pattern of the XRD is shown in Figure 14. Where $\mathrm{C}$ is calcite, $\mathrm{Q}$ is quartz, and $\mathrm{CH}$ is calcium hydroxide, 


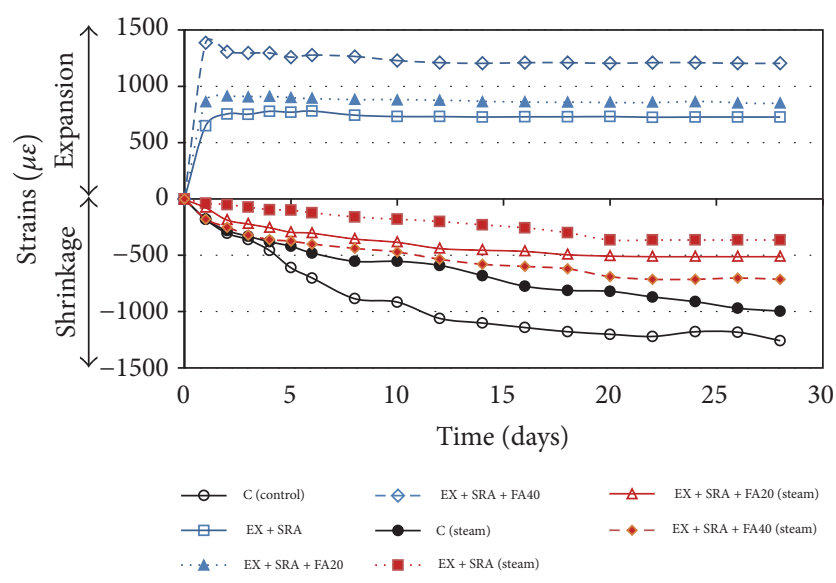

FIGURE 13: Total shrinkage results for EX + SRA and EX + SRA + FA (1 day after mixing).

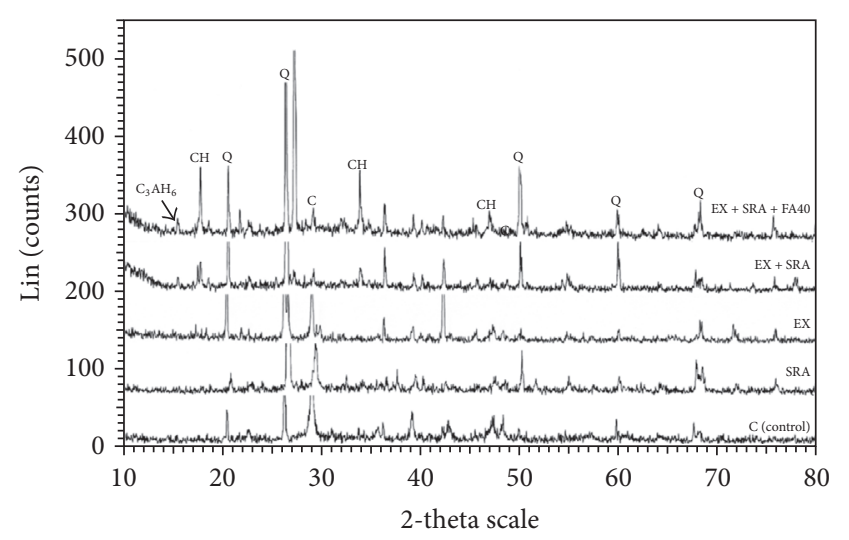

FIGURE 14: XRD results for steam-cured mortar.

the test result helps confirming the effects on the compressive strength and the shrinkage especially in the case of SRA + EX $+\mathrm{FA}$, of which the calcium hydroxide is highly found as well as $\mathrm{C}_{3} \mathrm{AH}_{6}$ which derives from the aluminate reaction of $\mathrm{C}_{3} \mathrm{~A}$ at higher than $60^{\circ} \mathrm{C}$, resulting in the hydrogarnet decreasing the strength of mortar and increasing the enlargement of the paste in the early age $[25,26]$.

The long-term shrinkage of the EX + SRA and EX + SRA + FA is shown in Figure 13 for the normal curing. The continuous enlargement and the long-term shrinkage were highly found and the calcium hydroxide is found in large amount after being steam-cured resulting in the high enlargement of the mortar during the early age. Such high shrinkage may be explained by the continuous pozzolanic reaction of the FA. While the paste already contains a large number of calcium hydroxides, the high temperature of the curing also helps stimulating the increase of the pozzolanic reaction [23] which shows the strength index that is higher than the normal curing, especially the mortar with $40 \%$ of FA added.

\section{Discussion}

The expansion strains need to be explained according to the single addition of SRA or EX and mixed addition of SRA and EX. The expansive mechanism of the increasing volume of gel state during the early age of the EX may occur from several factors such as the expansion from water adsorption, the crystal growth from the crystalline structure development of calcium hydroxide, and forming of coexisting pores from the disintegration of the ingredients within the EX during the hydration process [27]. There is a rate of change in volume of the chemical compounds of calcium hydroxide which increases from the reaction of $\mathrm{CaO}+\mathrm{H}_{2} \mathrm{O}=1.9$ times [27]. The expansion considerably concerns the solubility. The circulation of $\mathrm{Ca}^{+}$creates calcium hydroxide as the quantity of $\mathrm{Ca}^{+}$that decreases in the mixture [28].

For specimens EX, EX + FA20, and EX + FA40 after being steam-cured, the shrinkage rate is higher than those being normal-cured due to the better reaction of the steam curing that affects the EX during the early age. We notice that the steam curing during the early age leads the EX, EX + FA20, and EX + FA40 to extreme expansion, which agrees with Maltese et al. [24] who tested both the normal and water curing. That is to say, when the calcium oxide is embedded in the cement matrix, it is found that to treat the EX with merely normal curing is not sufficient for perfect reaction to occur. Therefore, to add water by water curing helps to enhance the calcium oxide hydration reaction better than the normal curing. The explanation for the increasing expansion of EX + FA20 and EX + FA 40 is that to increase the amount of $\mathrm{CaO}$ added to the mixture because the fly ash has such substances as $\mathrm{SO}_{3}$ and $\mathrm{CaO}$ as its composition that might play a role in helping the expansion reaction which leads the mortar to increase its expansion rate [29]. Furthermore, the expansion that occurs after being steam-cured can be further explained by Shi et al. [30] reporting that the reaction occurrence of $\mathrm{CaO}$ depends on the source, that is, from pure $\mathrm{CaCO}_{3}$ reagent or from industrial limestone powder, including the temperature used in the heating process. Low temperature lessens the duration of the hydration reaction while high temperature extremely lengthens the duration of the hydration reaction. In addition, the hydration rate of $\mathrm{CaO}$ considerably concerns the hydration reaction temperature. The increasing of hydration reaction temperature helps the reactant obtain enough energy to surmount the reaction of the potential barrier and thus increases the reaction rate effectively by helping the molecules of $\mathrm{CaO}$ and $\mathrm{H}_{2} \mathrm{O}$ to increase the kinetic energy in the ionization process and to empower the forming an activated complex. As such, the temperature used in curing affects the expansion accordingly [31]. The fact that the FA is heated in high temperature therefore affects the continuity of the expansion duration of mortar with EX + FA in the first date which might be a result from the reaction occurring in different periods of time for $\mathrm{CaO}$ in the mixture and there is low stiffness for mortar during the early age allowing the expansion to occur easily. After the steam curing, parts of $\mathrm{CaO}$ with reversible reaction and the FA which consists of $\mathrm{CaO}$ with slower reaction of EX may slightly affect the expansion after the first date while, 


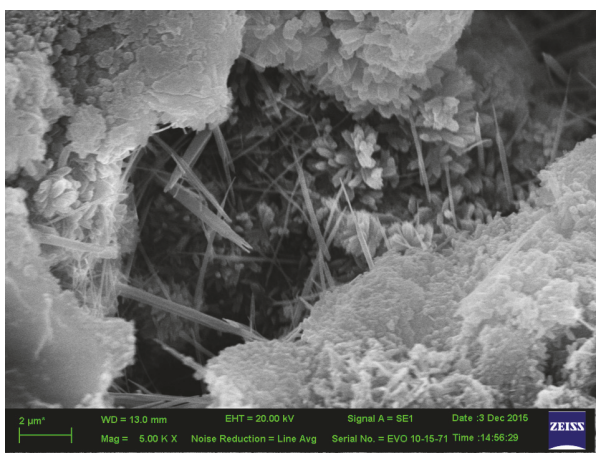

(a)

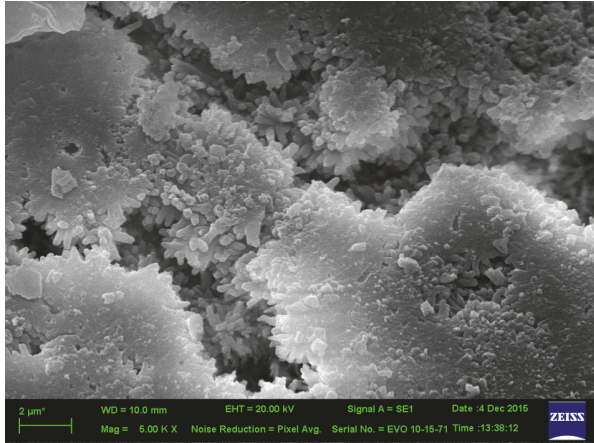

(b)

FIGURE 15: SEM of mortar with 2\% SRA: (a) cured at $30^{\circ} \mathrm{C}$; (b) steam-cured at $65^{\circ} \mathrm{C}$.

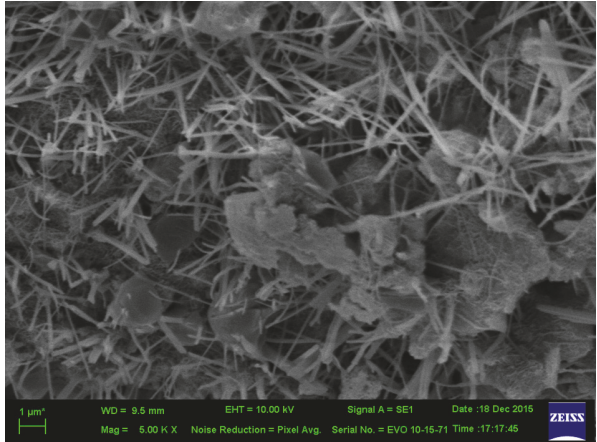

(a)

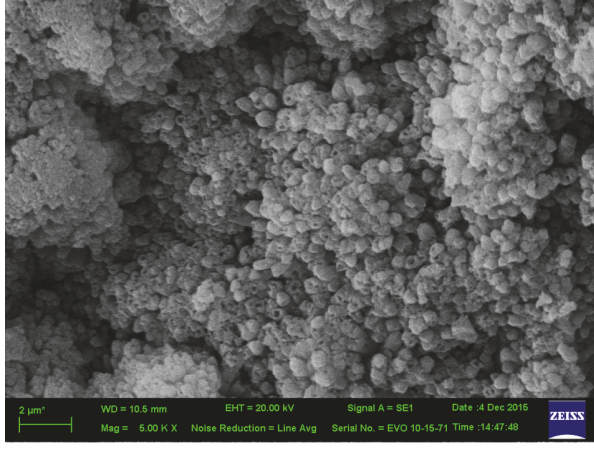

(b)

FIGURE 16: SEM of mortar with $15 \% \mathrm{EX}+2 \%$ SRA: (a) cured at $30^{\circ} \mathrm{C}$; (b) steam-cured at $65^{\circ} \mathrm{C}$.

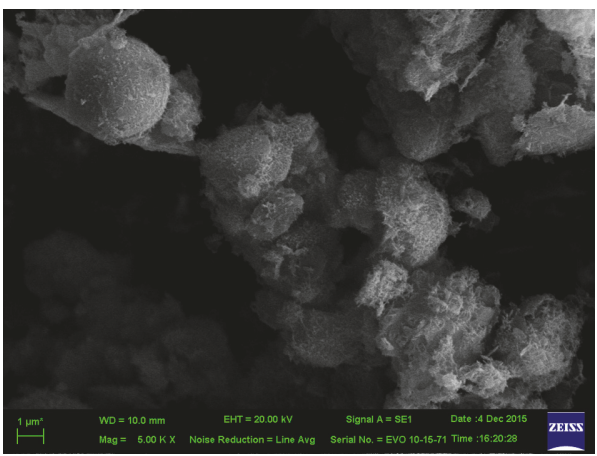

(a)

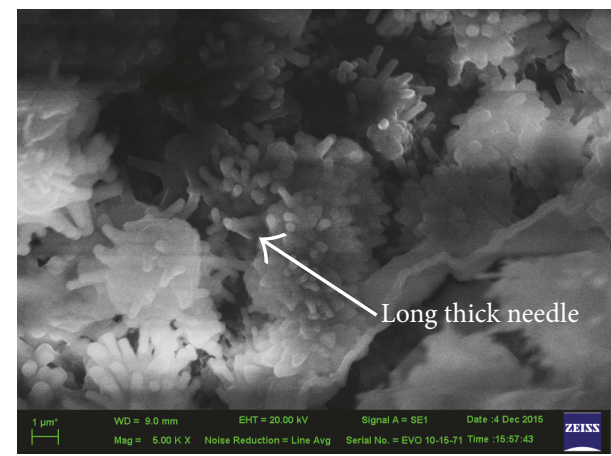

(b)

FIgURE 17: SEM of mortar with $15 \%$ EX $+2 \%$ SRA $+40 \%$ FA: (a) cured at $30^{\circ} \mathrm{C}$; (b) steam-cured at $65^{\circ} \mathrm{C}$.

mostly for the normal curing, the reaction of $\mathrm{CaO}$ is still incomplete affecting better continuity of expansion than the steam curing after the early age.

Not only does the mechanism in reducing the shrinkage of SRA help to reduce the surface tension of pore solution but it is also found that the quantity of SRA on the surface which is in direct contact with the air is higher than that deep down inside the sample piece due to the difference in capillary forces; the surface layer is no longer able to draw the water from the higher surface tension water below [32].
In the case of EX + SRA, apart from the occurrence of elongated crystals. José Oliveira et al. [33] explained the efficiency of mixing the SRA and the EX that it is from the Free Lime Hydration and the occurrence of ettringite formation within the pores of the structure. This produces the internal pressure which depends on the durability of the structure. When the SRA is added, both the initial and final setting times considerably delay. The totality from these factors is therefore explained in terms of reducing the plastic shrinkage. 


\section{Conclusions}

Effects of mortar added with EX, SRA, and FA through the normal and steam curing were studied and recorded in this research. The test results are summarized hereinafter:

(1) To add the EX and SRA including the FA helps increasing the enlargement of mortar during the early age more than using the sole EX or SRA.

(2) The steam curing helps reducing the plastic shrinkage. The mortar added with the EX and SRA increases the enlargement during the early age two times compared to the normal curing. In this regard, careful attention should be paid in case of excessive enlargement when the EX, SRA, and FA are added.

(3) Having been steam-cured, mortar with the sole SRA added gives the shrinkage result which is close to being normal-cured.

(4) The compressive strength of mortar with the EX, SRA, and FA added reduces in accordance with the higher proportion of cement and water replacement.

(5) The steam curing increases the compressive strength of mortar for all types of mixture, especially for mortar added with EX + FA and EX + SRA + FA.

\section{Conflicts of Interest}

The authors declare that they have no conflicts of interest.

\section{Acknowledgments}

This work is supported by Faculty of Engineering, King Mongkut's Institute of Technology Ladkrabang, Bangkok, Thailand (Grant no. 15 (2014)). The researchers would like to acknowledge the Water Loss Operation Section (MWA), Thailand, for the help provided in this regard.

\section{References}

[1] E. Holt and M. Leivo, "Cracking risks associated with early age shrinkage," Cement and Concrete Composites, vol. 26, no. 5, pp. 521-530, 2004.

[2] P. Lura, B. Pease, G. B. Mazzotta, F. Rajabipour, and J. Weiss, "Influence of shrinkage-reducing admixtures on development of plastic shrinkage cracks," ACI Materials Journal, vol. 104, no. 2, pp. 187-194, 2007.

[3] J. Saliba, E. Rozière, F. Grondin, and A. Loukili, "Influence of shrinkage-reducing admixtures on plastic and long-term shrinkage," Cement and Concrete Composites, vol. 33, no. 2, pp. 209-217, 2011.

[4] K. C. G. Ong, L. R. Chandra, and K. Myint-Lay, "Early-age shrinkage strains versus depth of low water-cement ratio mortar prisms," ACI Materials Journal, vol. 107, no. 3, pp. 213-221, 2010.

[5] P. Carballosa, J. L. García Calvo, D. Revuelta, J. J. Sánchez, and J. P. Gutiérrez, "Influence of cement and expansive additive types in the performance of self-stressing and self-compacting concretes for structural elements," Construction and Building Materials, vol. 93, pp. 223-229, 2015.
[6] S. Monosi, R. Troli, O. Favoni, and F. Tittarelli, "Effect of SRA on the expansive behaviour of mortars based on sulphoaluminate agent," Cement and Concrete Composites, vol. 33, no. 4, pp. 485489, 2011.

[7] C. Han, M. Han, S. Song et al., "Drying shrinkage of concrete combining expansive additives and shrinkage reducing agent," Journal of the Korea Concrete Institute, vol. 18, no. 3, pp. 397-404, 2006.

[8] A. A. Ramezanianpour, M. H. Khazali, and P. Vosoughi, "Effect of steam curing cycles on strength and durability of SCC: a case study in precast concrete," Construction and Building Materials, vol. 49, pp. 807-813, 2013.

[9] E. Tazawa, "Autogenous shrinkage of concrete," in Proceedings of the international workshop organized by JCI (Japan concrete institute), E \& FN Spon, Hiroshima, Japan, 1998.

[10] A. Ghoddousi, M. Raissghasemi, and T. Parhizkar, "A comparision between plastic shrinkage of concrete containing silica fume and the normal concrete," International Journal of Civil Engineering, vol. 5, no. 4, pp. 266-273, 2007.

[11] O. S. B. Al-Amoudi, M. Maslehuddin, M. Shameem, and M. Ibrahim, "Shrinkage of plain and silica fume cement concrete under hot weather," Cement and Concrete Composites, vol. 29, no. 9, pp. 690-699, 2007.

[12] Y. Baba and T. Kasai, "Shrinkage characteristics of cement paste and mortar at very early ages," Zairyo/Journal of the Society of Materials Science, Japan, vol. 56, no. 3, pp. 294-301, 2007.

[13] H. Yazici, S. Aydin, H. Yiğiter, and B. Baradan, "Effect of steam curing on class $\mathrm{C}$ high-volume fly ash concrete mixtures," Cement and Concrete Research, vol. 35, no. 6, pp. 1122-1127, 2005.

[14] H. Zhimin, L. Junzhe, and Z. Kangwu, "Influence of mineral admixtures on the short and long-term performance of steamcured concrete," Energy procedia, vol. 16, pp. 836-841, 2012.

[15] D. W. S. Ho, C. W. Chua, and C. T. Tam, "Steam-cured concrete incorporating mineral admixtures," Cement and Concrete Research, vol. 33, no. 4, pp. 595-601, 2003.

[16] D. P. Bentz, M. R. Geiker, and K. K. Hansen, "Shrinkagereducing admixtures and early-age desiccation in cement pastes and mortars," Cement and Concrete Research, vol. 31, no. 7, pp. 1075-1085, 2001.

[17] J. Weiss, P. Lura, F. Rajabipour, and G. Sant, "Performance of shrinkage-reducing admixtures at different humidities and at early ages," ACI Materials Journal, vol. 105, no. 5, pp. 478-486, 2008.

[18] J. J. Biernacki, P. J. Williams, and P. E. Stutzman, "Kinetics of reaction of calcium hydroxide and fly ash," ACI Materials Journal, vol. 98, no. 4, pp. 340-349, 2001.

[19] P. Chindaprasirt, C. Jaturapitakkul, and T. Sinsiri, "Effect of fly ash fineness on compressive strength and pore size of blended cement paste," Cement and Concrete Composites, vol. 27, no. 4, pp. 425-428, 2005.

[20] M. Narmluk and T. Nawa, "Effect of curing temperature on pozzolanic reaction of fly ash in blended cement paste," International Journal of Chemical Engineering and Applications, vol. 5, no. 1, pp. 31-35, 2014.

[21] V. Corinaldesi, "Combined effect of expansive, shrinkage reducing and hydrophobic admixtures for durable self compacting concrete," Construction and Building Materials, vol. 36, pp. 758764, 2012.

[22] G. Sant, B. Lothenbach, P. Juilland, G. L. Saout, J. Weiss, and K. Scrivener, "The origin of early age expansions induced in 
cementitious materials containing shrinkage reducing admixtures," Cement and Concrete Research, vol. 41, no. 3, pp. 218-229, 2011.

[23] M. J. Oliveira, A. B. Ribeiro, and F. G. Branco, "Curing effect in the shrinkage of a lower strength self-compacting concrete," Construction and Building Materials, vol. 93, pp. 1206-1215, 2015.

[24] C. Maltese, C. Pistolesi, A. Lolli, A. Bravo, T. Cerulli, and D. Salvioni, "Combined effect of expansive and shrinkage reducing admixtures to obtain stable and durable mortars," Cement and Concrete Research, vol. 35, no. 12, pp. 2244-2251, 2005.

[25] H. F. W. Tayler, Cement Chemistry, 2nd edition, 1990.

[26] J. Bensted and P. Barnes, Structure and performance of cements second edition, pp. 119-121, 2002.

[27] S. Nagataki and H. Gomi, "Expansive admixtures (mainly ettringite)," Cement and Concrete Composites, vol. 20, no. 2-3, pp. 163-170, 1998.

[28] S. Chatterji, "Mechanism of expansion of concrete due to the presence of dead-burnt $\mathrm{CaO}$ and $\mathrm{MgO}$," Cement and Concrete Research, vol. 25, no. 1, pp. 51-56, 1995.

[29] A. Nawaz, P. Julnipitawong, P. Krammart, and S. Tangtermsirikul, "Effect and limitation of free lime content in cement-fly ash mixtures," Construction and Building Materials, vol. 102, pp. 515-530, 2016.

[30] H. Shi, Y. Zhao, and W. Li, "Effects of temperature on the hydration characteristics of free lime," Cement and Concrete Research, vol. 32, no. 5, pp. 789-793, 2002.

[31] O. Mitsuo, K. Suhara, and H. Morimoto, "Expansion energy and hydration products of expansive mortar at different temperatures," in Proceedings of the Third International Conference on Sustainable Construction Materials and Technologies, 10, pp. 101, 2013.

[32] D. P. Bentz, "A review of early-age properties of cement-based materials," Cement and Concrete Research, vol. 38, no. 2, pp. 196204, 2008.

[33] M. José Oliveira, A. B. Ribeiro, and F. G. Branco, "Combined effect of expansive and shrinkage reducing admixtures to control autogenous shrinkage in self-compacting concrete," Construction and Building Materials, vol. 52, pp. 267-275, 2014. 

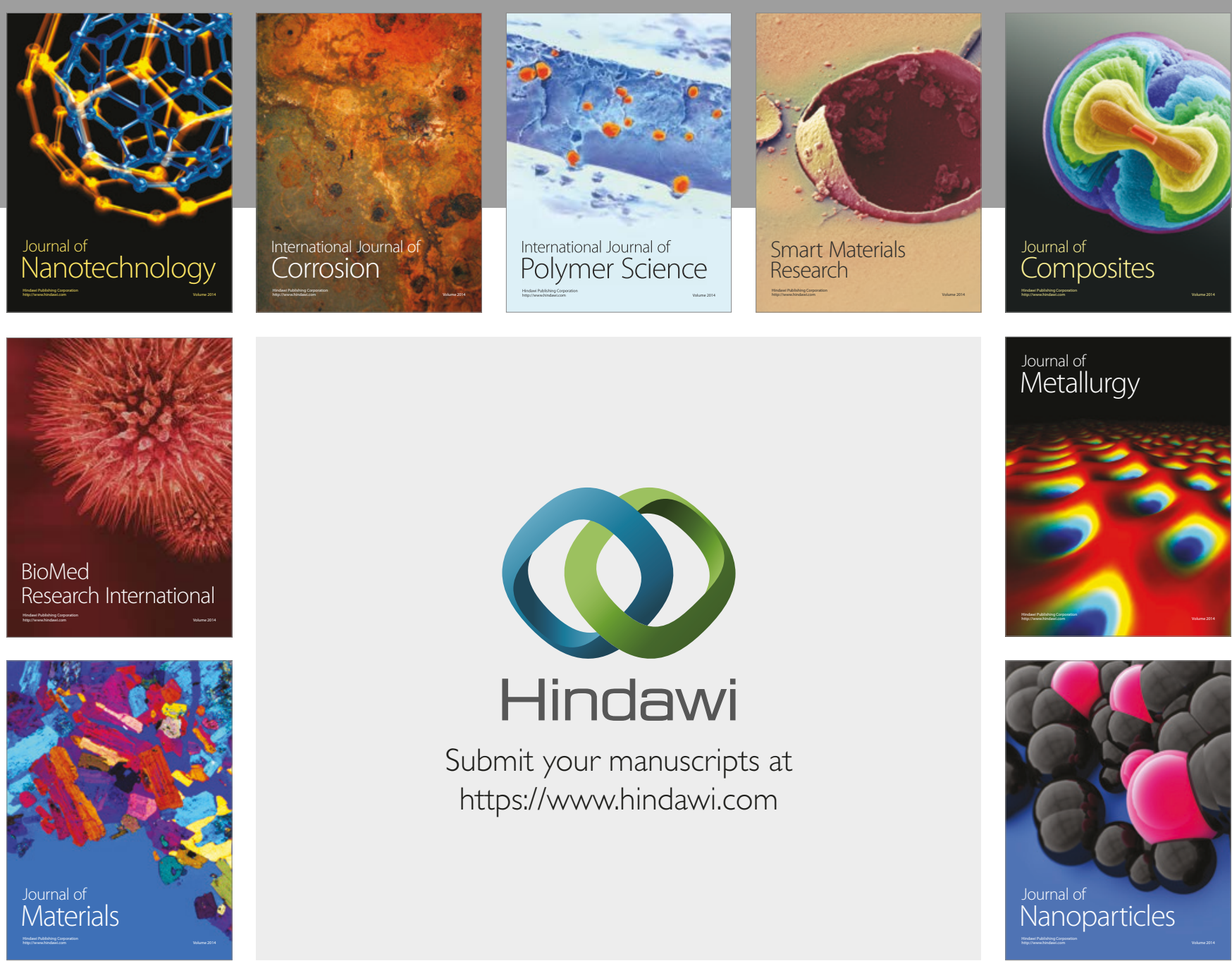

\section{Hindawi}

Submit your manuscripts at

https://www.hindawi.com
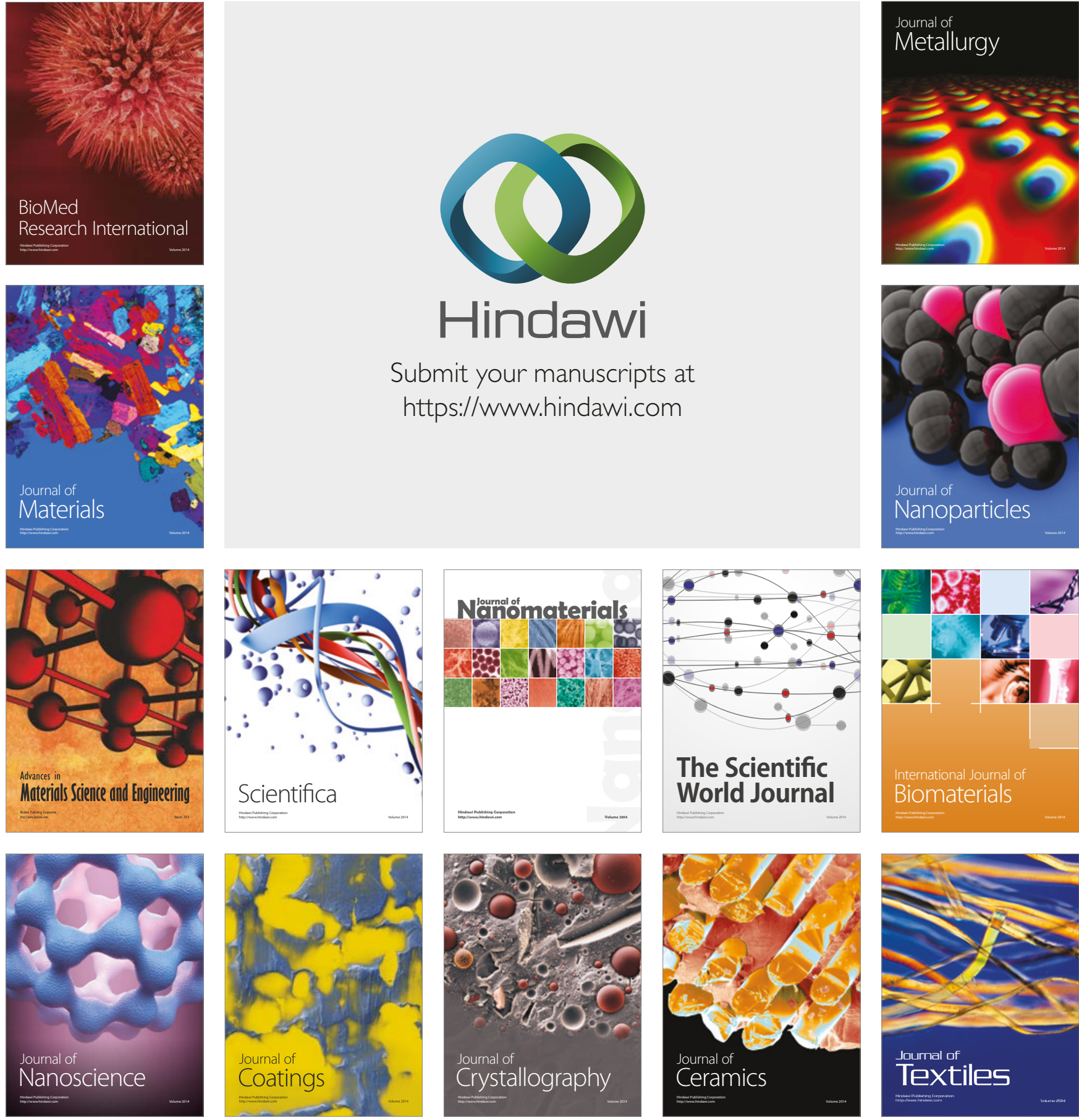

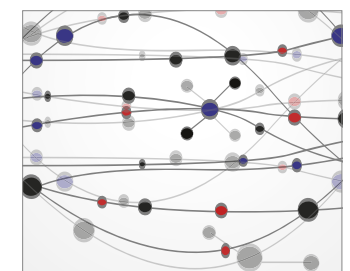

The Scientific World Journal
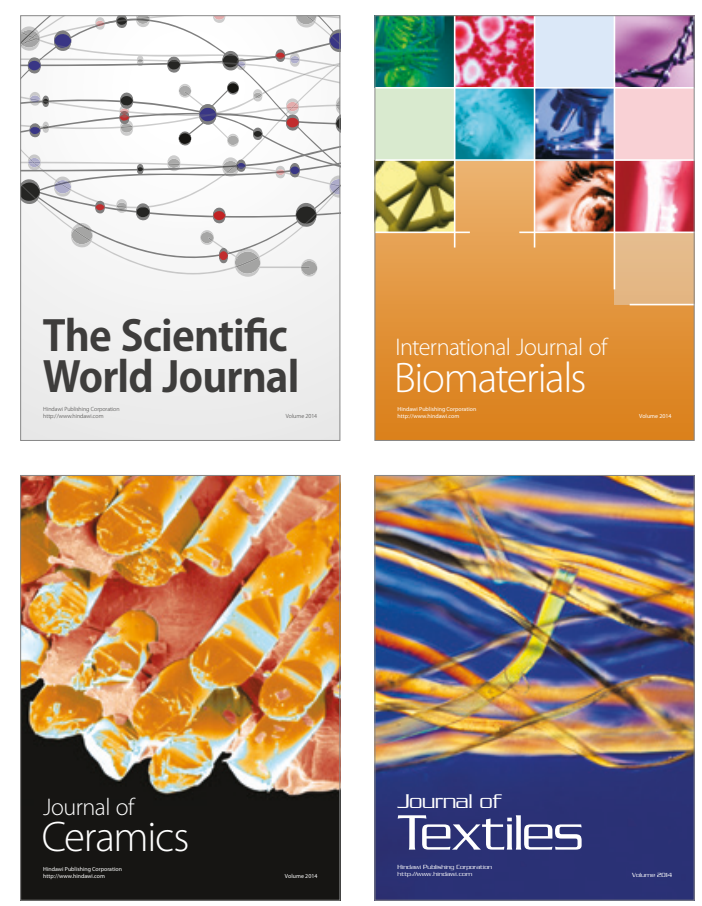